\title{
Percursos dissidentes no mercado pornográfico brasileiro
}

\section{Nas redes do sexo: os bastidores do pornô brasileiro.}

DÍAZ-BENÍTEZ, María Elvira.

Rio de Janeiro: Zahar, 2010.

María Elvira Díaz-Benítez é colombiana e possui graduação em Antropologia pela Universidad Nacional de Colombia, em 1998; mestrado e doutorado em Antropologia Social pelo Museu Nacional, Universidade Federal do Rio de Janeiro, em 2005 e 2009, respectivamente. É pesquisadora do Centro Latino-Americano em Sexualidade e Direitos Humanos, Instituto de Medicina Social (IMS), Universidade do Estado do Rio de Janeiro. Atua principalmente nas áreas de relações de gênero, étnico-raciais, práticas sexuais dissidentes e pornografia, tendo realizado dissertação de mestrado sobre negros homossexuais no Brasil e na Colômbia e tese de doutorado sobre a indústria pornográfica brasileira, ambos sob a orientação de Gilberto Velho.

O livro aqui resenhado, fruto de sua tese, apresenta uma pesquisa sobre a indústria pornográfica brasileira que se destaca por ser a primeira realizada a partir de observação participante, o que the assegura um caráter inovador, considerando que o campo de observação direta de contextos de interação sexual ainda não é consolidado no Brasil. A autora realizou seu trabalho de campo, ao longo de um ano e meio, com cinco empresas que produzem filmes pornográficos não ilegais ou "bizarros", e manteve um foco nas microrredes relacionais que estão presentes nos diversos "tentáculos do sexo". Durante esse período, Díaz-Benítez observou, conversou, conviveu e viveu em contato com os diversos participantes desse universo, como diretores, atores, criadores, recrutadores, produtores. Indico a leitura do livro Nas redes do sexo: os bastidores do pornô brasileiro por ser uma grande contribuição aos campos de estudos de gênero e sexualidade, uma vez que dá voz aos diferentes personagens que compõem esse 
universo e traz um olhar apurado e denso dessa realidade que vai além de visões estereotipadas, vitimizantes ou preconceituosas.

O livro apresenta as redes da indústria pornográfica brasileira e seus diversos atores, e oferece um panorama dos tipos de filmes que têm sido produzidos e consumidos no Brasil e em outros países. É dividido em quatro capítulos, que relatam as etapas da produção e da comercialização da pornografia no país. No primeiro capítulo, "Preliminares", a autora nos conta sobre o recrutamento, o casting, os processos de seleção e os rituais pré-filmagem. No segundo, "Transa", indica as formas como o sexo pornográfico é encenado, mostrando as práticas mais tradicionais e algumas possibilidades de variação. No terceiro, "Consumação", aponta a forma como é terminado o sexo cenográfico e também a produção do material filmado e fotografado. O último capítulo, "Elenco", oferece informações sobre a vida de algumas pessoas que acompanhou ao longo da pesquisa, destacando suas formas de envolvimento na indústria, percepções, relacionamentos afetivos.

Seu relato etnográfico desses contextos marcados pelo erotismo e, por isso, estigmatizados e estigmatizantes é detalhado, denso, instigante e sedutor. A partir dele a autora nos leva para dentro desse mundo, permitindo-nos ter acesso a sensações e sentimentos que marcam tanto os participantes como a própria pesquisadora. Ela destrincha as etapas dos filmes, mostrando-nos como esses retratam um sexo coreográfico que segue determinada sequência e forma de fazer, embora haja distinções relativas ao público-alvo e aos atores, o que nos permite compreender a todos sob uma ótica semelhante. Por outro lado, evidencia suas estratégias e dificuldades de inserção no campo de pesquisa e as formas como foi aprendendo as regras específicas daquele contexto em que o erotismo está presente, mas não deve ser manifesto a todo momento nem de todas as formas. Assim, falanos da necessidade da repressão do pudor e também do desejo, mas também da possibilidade de uso do tesão e da vergonha da pesquisadora como forma de conseguir dados de campo.

O livro é uma grande contribuição aos campos de estudos de gênero e sexualidade, uma vez que apresenta como essas noções se constituem, articulam e são ressignificadas nessa realidade, que se mostra, a um só tempo, marcada por transgressões e discursos conservadores.

Os discursos conservadores estão presentes no público, prioritariamente masculino, ao qual são destinadas as produções e também na busca por corpos marcados por estereótipos de gênero, seguindo paradigmas hegemônicos de beleza. No caso do pornô heterossexual, existem estruturas binárias do gênero e das relações sexuais que produzem um hipergênero, com masculinidades e feminilidades excessivas, havendo marcadores corporais claros que evidenciam ideais estanques de feminilidade $e$ de masculinidade. Os corpos associados à feminilidade (seja de mulheres, seja de travestis) são os passíveis de "serem penetrados" e devem ser "superfemininos", mostrando partes corporais como as nádegas ou os seios, mesmo junto com um pênis, no caso das travestis femininas. Os corpos masculinos devem ser também "supermasculinos", responsáveis pela penetração e com grande enfoque na virilidade e na força. Essa dicotomia se torna menos presente apenas em relação a filmes bissexuais ou homossexuais, nos quais nem sempre as fronteiras são tão claras, embora mesmo nos filmes gays haja uma busca maior por garotos musculosos, salvo exceção para o caso de meninos que têm aparência de muito jovens, os chamados "lolitos" ou "ninfetos".

Em relação à orientação sexual, existem também discursos conservadores e semelhantes aos presentes em ambientes não pornográficos. No caso dos homens, há um constante medo entre os que não se autoidentificam como homossexuais de serem percebidos com essa orientação, o que leva à evitação de algumas práticas sexuais e posições, além de uma constante afirmação de que "não são gays" e de que não têm desejos homoeróticos. Entre as mulheres o fato de ser lésbica ou bissexual não interfere em seu capital simbólico nesse mercado. Observo que a disponibilidade feminina para estar com outras mulheres é algo inclusive muito valorizado em diversos contextos além do pornográfico, em que as relações entre mulheres são vistas como eróticas e incentivadas pelos homens.

A autora apresenta que o mercado de produção de filmes pornográficos é responsável também por transgressões e ressignificações das relações de gênero e sexualidade. Esse ponto é fundamental, haja vista que a pornografia é frequentemente rechaçada por feministas por considerarem que coloca as mulheres em relações de submissão e que reitera relações hierárquicas. Muitas vezes se espera das mulheres "boas" que essas não sintam desejo, que vinculem o prazer ao afeto e que não gostem de práticas consideradas vulgares ou inadequadas (como 0 sexo anal ou grupal). Já no sexo pornográfico as 
mulheres devem gostar de sexo de forma independente do afeto, apreciar as diversas práticas e gozar e o tesão efetivamente sentido é profundamente valorizado. Muitas vezes as atrizes nesses filmes buscam as relações sexuais e explicitam seus prazeres, deixando claro o que desejam e como desejam, em alguns momentos até mesmo aparentando ser quase insaciáveis, querem realizar sexo da forma que gostam, e esse é completamente deslocado do dispositivo do amor romântico. Nesses casos, essas mulheres são simbolicamente masculinizadas por sua atitude de excesso e de transgressão dos modelos de sexualidade feminina, sendo o corpo e o sexo o veículo através do qual ocorre essa ressignificação. Nesse sentido, a pornografia bem como a prostituição podem se mostrar como ambientes em que subjetividades e opções sexuais podem ser mais livremente expressas e alcançadas.

Apesar da valorização do prazer feminino, o orgasmo que é altamente enfatizado é o masculino. As mulheres demonstram o gozo apenas por sons ou palavras, e os homens sempre devem ejacular para que seu gozo fique evidenciado. Ademais, a ejaculação sempre recai sobre os corpos feminizados (mulheres, travestis, passivos), o que permite evidenciar enunciados de gênero hierarquizados.

As justificativas para a inserção no mercado pornográfico se mostram como possibilidade também de transgressão e de conservação de relações de gênero. Dentre as mulheres, a maioria afirma que o objetivo é o dinheiro, o que seria uma transgressão, na medida em que coloca o sexo como algo que pode ser negociado financeiramente, mas por outro lado é conservador, ao apagar as possibilidades de justificativas relativas ao prazer ou à experimentação. No caso dos homens, a justificativa do prazer ou do gosto pelas praticas sexuais é muito mais presente, pois essa é considerada mais legítima. Existem em ambos os casos relatos de que o mercado do sexo é também interessante por sua flexibilidade de horários, privilégios oferecidos, sociabilidade e autonomia. A autora demonstra que há sempre uma possibilidade de escolha, em que os indivíduos buscam atingir objetivos e optam em meio a possibilidades e limitações. Essa reflexão também é muito importante por questionar visões de algumas feministas de que a inserção no mercado do sexo seria fruto de uma escravidão ou dominação e por mostrar que há a possibilidade de agência no campo da pornografia e também uma busca por formas mais livres de expressão da sexualidade e da afetividade.
É muito interessante a forma como a autora destaca a capacidade subversiva da indústria pornográfica, mas sem deixar de evidenciar que essa muitas vezes se mostra enfraquecida através de formatos que reforçam as diferenças de gênero e suas hierarquias. Um exemplo disso são as estéticas de violência: como os filmes que encenam estupros, nos quais a mulher é colocada como frágil, indefesa, alvo de humilhação, enquanto o homem é forte, rude e dominador. Apesar disso, a autora não se posiciona dentre as pessoas que consideram que essas estéticas do estupro gerariam a violência na vida real.

O universo da pornografia, visto do exterior, parece ser aquele em que tudo é permitido e aceito, mas a partir das análises de María Elvira Díaz-Benítez percebemos que são configuradas regras e convenções morais que determinam as formas de se comportar, os limites do que é aceito ou não, e que essas normas criam hierarquias que classificam as participantes. Pode haver uma reiteração de convenções externas ou o reordenamento dessas, com a colocação de novos valores, e ainda essas não serem fixas, podendo ocorrer negociações no caso de o transgressor ser uma pessoa de prestígio, querida ou de boa posição hierárquica na rede. Considera-se que aqueles que não conhecem ou não seguem as regras não se valorizam e que os diretores e produtores que colocam atrizes e atores nessa posição são pessoas que não valorizam ou cuidam de seu elenco.

Os filmes considerados bizarros, como os que incluem escatologia e zoofilia, são por vezes lançados pelas produtoras com outros selos para manter os segmentos separados e não prejudicar a imagem da empresa, além de serem os mais mal pagos. $O$ público que assiste a esses filmes é considerado "depravado, maluco, pervertido". Já os atores que aceitam participar dessas filmagens são vistos como "tranqueira", podendo inclusive não serem mais chamados para fazer os demais tipos de filmes. As regras internas que governam essas moralidades são colocadas em prática via métodos sutis de controle social, como a fofoca, ou até mesmo através de uma exclusão das próximas produções ou de uma negação de contracenar com os atores e as atrizes. O peso do estigma não recai sobre todo o pornô, mas principalmente sobre essas práticas tidas como bizarras, e os transgressores são por vezes vistos como usuários de droga ou perversos, já que se considera que têm prazer nessas situações. 
A autora propõe uma categoria muito interessante para se referir às trajetórias dos personagens dessa rede que é a de percursos dissidentes. Com essa categoria visa destacar o caráter transgressor da profissão e dos roteiros percorridos, como a adoção de práticas, estilos de vida e modelos de relacionamentos que divergem dos tradicionais. A dissidência é fruto da autoafirmação e não é absoluta em todos os domínios da vida, o que permite que seja ou não acionada nos diversos contextos, havendo fronteiras sutis e em movimento. Já a ideia de percursos remete a carreiras não lineares, mas móveis, em deslocamento, com características diversas nas experiências individuais. A categoria percursos dissidentes traz em si também a ideia de ética do instante, marcando uma efemeridade nos códigos de interação, já que, segundo a análise que faz, a permanência do sujeito no mercado da pornografia é curta e há uma ausência de expectativas de compromissos duradouros para o futuro.

María Elvira Díaz-Benítez não foca apenas na inserção no universo pornográfico, mas busca conhecer o trânsito de seus personagens por outros ambientes e as formas como as dissidências criam novas regras e convenções, bem como novas formas de relacionamento sexual e afetivo. São comuns relatos de atores e atrizes que preferem se relacionar com pessoas do mesmo meio, já que essas entendem as rotinas de trabalho e os hábitos e são menos "ciumentas" em relação às cenas de sexo por não considerarem haver infidelidade, uma vez que não há sentimentos de afeto romântico e há a troca financeira. Buscam ainda alguém que não use o trabalho sexual como forma de manipulação, devendo ter uma postura de não obrigar ou estimular a inserção nessa atividade, mas de compreender. A relação sexual de um homem com outro também é ressignificada, e algumas mulheres até preferem que seus parceiros interajam com homens ou travestis para assegurar que não haverá infidelidade no que diz respeito ao gênero da parceira. Já para outras a experimentação é algo essencial e que não afeta a orientação sexual. As relações familiares e de amizade frequentemente são marcadas também pela transgressão, que pode gerar rechaço do membro ou do grupo. Esse ocorre principalmente entre as mulheres, já que muitas vezes travestis e gays já afrontaram suas famílias em outros momentos, e entre homens é permitida e valorizada a experimentação. Algumas pessoas mantêm separada sua vida profissional, adotando duas identidades, o que objetiva evitar esses efeitos, mas também atuam como um limite simbólico que determina que não são atores ou atrizes o tempo inteiro, já que alguns adotam estilos de vida que nem sempre coincidem com o universo da pornografia.

Letícia Cardoso Barreto Universidade Federal de Santa Catarina Miriam Pillar Grossi Universidade Federal de Santa Catarina 